\title{
Prevalence of Ovine Gastrointestinal Nematodes in Meskan District, Gurage Zone, Southern Ethioipa
}

\author{
Tesfalem Nana (Dr.) \\ Veterinary Worker at Humbo District Livestock and Fish Development Office, Wolaita Zone, SNNPRs, Ethiopia
}

\begin{abstract}
A cross sectional study was conducted with the objectives of determining the prevalence and risk factors associated with ovine major gastrointestinal nematodes in Meskan district, Gurage zone from November 2014 to April 2015. A fresh faecal sample of approximately $10 \mathrm{~g}$ was collected directly from the rectum of 350 sheep by using gloved fingers. All statistical analysis was performed using statistical software packages for social science (SPSS) version 20. From the total 350 local sheep breed examined, $212(60.6 \%)$ were found infected with different types of gastro-intestinal nematodes. Strongyles were the most frequently $95(27.1 \%)$ recovered nematode eggs followed by Strongyloides 38 (10.9\%), Trichuris species $13(3.7 \%)$ and Ascaris spps $2(0.6 \%)$. There was significant association $(\mathrm{p}<0.05)$ between the gastrointestinal nematode infection and animals with different age and sex group. However, there was no significant difference $(p>0.05)$ in prevalence between body condition and different study sites of the subject area. Due to its important health problem and impact on production in the study area, emphasis should be given for the control and prevention of gastrointestinal nematode infection with further studies on genus and species identification by using further laboratory techniques.
\end{abstract}

Keywords: Nematode, Meskan distric, Gastrointestinal nematode, Prevalence, Sheep

\section{INTRODUCTION}

Sheep and goats are the most numerous of man's domesticated livestock and are especially important in more extreme climates of the world. Africa hosts 205 and 174 million sheep and goats representing 17 and 13 percent of the world total small ruminant population, respectively. The population of small ruminants in sub-Saharan Africa is estimated to be 274 million (Samson and Frehiwot, 2010). Ethiopia is believed to have the largest livestock population in Africa (Tilahun and Schmidt, 2012) and (CSA, 2013). Naturally endowed with different agro-ecological zones and suitable environmental conditions, the country is a home for many livestock species and suitable for livestock production. An estimate indicates that the country is a home for about 54 million cattle, 25.5 million sheep and 24.06 million goats. With these figure the country is the second in Africa, and the sixth in the world, in terms of sheep population (CSA, 2013).

Sheep and goats are of great importance as major sources of livelihood and contribute to the sustenance of landless, smallholder and marginal farmers especially to the poor in the rural areas throughout the developing countries. Studies have revealed that ruminants contribute $80 \%$ of the total food production from livestock in tropical Africa, of which small ruminants account for about $22 \%$. Sheep and goats are very important for resource-poor smallholder systems of rural Ethiopia due to their ease of management, short generation cycles and high reproductive rates which lead to high production efficiency and significant role in provision of food and generation of cash income. They serve as a living bank for many farmers, closely linked to the social and cultural life of resource poor farmers and provide security in bad crop years (Tsedeke, 2007).

Globally parasitic diseases continue to be a major constraint especially for poor developing countries.. Most of the losses that come from the parasite are shared by the gastro-intestinal helminthes. Therefore, helminthes infections in small ruminants are serious problems in the developing world, particularly where nutrition and sanitation are poor (Thrusfield, 2005). Besides, gastro-intestinal nematode infection is also a major health problem in the world. Furthermore, these nematode infections affect the health of millions of people and animals, causing huge economic loss in livestock farming (Soulsby, 1982). In addition, nematode parasites are also a major problem for small ruminants. In these animal a range of nematode infection present as a mixed infection that mainly invade the small intestine and abomasums compartment of small ruminant. These group of parasites includes; Haemonchus, Cooperia, Ostertagia, Bunostomum, Trichostrongylus, Oesophagostomum and Nematodirus (Abebe and Esayas, 2001).

Smallholders and pastoralists may not easily detect the effect of helminths because of the subclinical nature of the infections (Soulsby, 1986) and (Urquhart et al., 1996). Thus, the sub-clinical nematode infections are responsible for significant economic losses. They are responsible for immune-suppression and enhancing the susceptibility of the animals to other diseases. Once the clinical diseases are noticed, such economic losses in terms of animal productivity have already occurred (Kaplan, 2006). In Ethiopia productivity losses due to helminth parasites are often substantial and a loss of US \$81.8 million is reported annually (Demelash et al., 2006).

In developed world, the greatest component of impact by these nematode parasites is probably found in 
the cost of control. But their impact is greater in the sub-Saharan Africa in general and Ethiopia is particular due to ecological factors suitable for diversified hosts and parasite species (Ragassa et al., 2006). The epidemiology of gastro-intestinal (GIT) parasites in livestock varied depending on the local climatic condition, such as humidity, temperature, rainfall, vegetation and management practices (Takelye, 1991). These factors largely determine the incidence and severity of various parasitic diseases in different region of the country. Thus, gastrointestinal nematode is one of the major problem of sheep production in the Meskan district, however, data on the distribution of the parasite in the area are lacking. On the other hand knowing the current situation of GI nematode of sheep in the area could be the basis for all possible actions including its control and prevention.

Therefore, the main objectives of this study are:-

$>$ To determine the prevalence of major gastrointestinal nematodes of sheep in Meskan district and,

$>$ To assess the potential risk factors associated with ovine gastrointestinal nematode infection in the study area and to forward base line data for further studies.

\section{MATERIALS AND METHODS}

\subsection{Study Area}

A cross sectional study was conducted from November 2014 to April 2015 to determine the prevalence of major gastrointestinal nematode parasites in sheep in Meskan district, which is one of the 12 districts of Gurage Zone in Southern Nations, Nationalities and People Regional State (SNNPRS), Ethiopia. The district consists of 40 peasant associations (PA's), which are the smallest administrative units in Ethiopia. The district is located 135 $\mathrm{km}$ away from Addis Ababa, in South West direction. The area is situated at midland with altitude of 1800 meter above sea level and exhibit a bimodal rainfall system (long and short rainy season) with average rainfall $1900 \mathrm{~mm}$. The long rainy season extends from June to September; whereas the short rainy season ranges from mid February to the end of April (Solomon and Rahmeto, 2010). Topographically the area is characterized by massive mountainous terrain in the western border of the district, whereas the eastern part is dominated by plane land. The maximum annual temperature does not exceed $26^{\circ} \mathrm{C}$ and mean minimum temperature varies from 11.2$19.2^{\circ} \mathrm{C}$. Communal grazing is in practice in some part of the area. Three different ethnic groups inhabit in the area namely, Guraghe, Mareko and Silti. Their living style similar and depends on agriculture, using mixed livestock-crop production. The main crop cultivated in the district are corn, wheat, teff, false banana, coffee, chat, barely and maize. The livestock population of the district is comprised of 125,000 cattle, 35,000 sheep, 23,000goats, 9100 horses, 800 mule, 11500 donkey and 55,000 poultry (MDARDB, 2013).

\subsection{Study Animals}

The study animals were all local breeds, kept under traditional extensive management system. Conventionally, those animals with the age of less than one year were considered as young while those greater than or equal to one year were included as adults according to the classification of age groups by (Kumssa et al., 2011). Body condition scoring of sampled animal was carried out according to the method described by (Cooper and Thomas, 1985) and categorized into three scores as poor, medium and good. The poor body condition was recorded when individual spinous process were sharp to touch and easily distinguished, in addition, the bony structure of the sheep were easily noticeable. The eye muscles have moderate depth. Medium body condition was recorded when the spinous process examined with very firm pressure and they were round rather than sharp. The eye muscle areas were full with moderate fat cover. Good body condition was recorded when the top and side of the back bone in loin area immediately behind the last rib and above the kidney were covered with muscles. The eye muscles were full and had a thick fat cover.

\subsection{Study Design}

A cross-sectional study design was used to determine the prevalence of sheep gastrointestinal nematodes in Meskan district based on coprological examination of nematode eggs.

\subsection{Sampling Method}

Out of 40 peasant associations (PAs) of Meskan district, five were selected purposely. The selected sites were: Enseno Usme, Dobana Gola, Wurb, Bamo and Gidena Aborat. Equal proportions of samples were collected from each site by simple random sampling technique was used to select study animals. Age, sex, site and body condition score were considered as risk factors for the occurrence of gastrointestinal nematode infections in sheep. The sample size was calculated according to the formula described by (Thrusfield, 2005). There was similar study done previously on the other part of Ethiopia, with overall prevalence of $68.1 \%$ gastrointestinal nematode parasite (Diriba and Birhanu, 2013). Accordingly using 68.1\% expected prevalence with 5\% absolute precision at $95 \%$ of confidence interval, the sample size determined was 334 but increased to 350 sheep. The peasant associations (PAs), body condition scores, estimated age group and sex were recorded. The formula for sample size determination is given below. 


$$
\mathrm{n}=\underline{1.96^{2} \mathrm{P}_{\exp }\left(1-\mathrm{P}_{\exp }\right)} \mathrm{d}^{2}
$$

Where; $\mathrm{n}=$ required sample size

$\mathrm{P}_{\exp }=$ expected prevalence

$\mathrm{d}^{2}=$ desired absolute precision

\subsection{Sample Collection and Examination Procedure}

A fresh faecal sample of approximately 10 gram was collected directly from the rectum of 350 sheep by using gloved fingers. Collected fecal samples were put in the sampling bottle containing $10 \%$ formalin and all the necessary information including body condition, sex, age and sites were collected was labeled. The collected samples were transported to Parasitology laboratory of Wolaita Soddo Regional Veterinary laboratory where they were stored at refrigerated temperature $\left(4^{\circ} \mathrm{C}\right)$ until processing. In laboratory, fecal samples were examined for the detection of nematode eggs using standard procedures of flotation as described by (Charles, 2006). In this study, the floatation solution used was $\mathrm{NaCl}$ (sodium chloride).

\subsection{Data Management and Analysis}

The collected data was coded into appropriate variables and entered in to MS excel worksheet. All statistical analysis was performed using statistical data packages for social science (SPSS) version 20. The prevalence was calculated by dividing the number of positive animals by the total number of animals examined and times 100 . Percentage $(\%)$ to measure prevalence and Chi-square $(\chi 2)$ was used to test the existence of differences in prevalence between age groups, sex, body condition scores and site of collection. In all the analyses, confidence level was held at $95 \%$ and $\mathrm{P}<0.05$ was set for significance.

\section{RESULTS}

\subsection{Prevalence of Gastrointestinal Nematodes of Sheep Encountered in the Study Area}

From the total 350 local sheep breed examined, 212 (60.6\%) were found infected with different types of gastrointestinal nematodes. The identified parasites were Strongyle type of eggs, Strongyloides, Ttrichuris Spps and Ascaris spps as single and mixed infection. Out of the total positive cases $212(60.6 \%), 148(42.3 \%)$ were infected with one nematode eggs type and $64(18.3 \%)$ were infected with two or more nematode eggs type. Strongyles were the most frequently 95 (27.1\%) recovered nematode eggs followed by Strongyloides $38(10.9 \%)$, Trichuris species 13 (3.7\%) and Ascaris spps 2 (0.6\%). Strongyle and strongyloides commonly encountered as mixed infection followed by Strongyle and Trichuris spps.

Table.1: Prevalence of gastrointestinal nematode parasite egg types of sheep encountered in the study area.

\begin{tabular}{|c|c|c|c|c|}
\hline Parasite egg types & No. of animal examined & $\begin{array}{l}\text { Positive } \\
\text { nematode eggs }\end{array}$ & Sample & Prevalence (\%) \\
\hline Strongyle spps. & 350 & 95 & & 27.1 \\
\hline Strongyloides spps. & 350 & 38 & & 10.9 \\
\hline Trichuris spps. & 350 & 13 & & 3.7 \\
\hline Ascaris spps & 350 & 2 & & 0.6 \\
\hline Mixed type & 350 & 64 & & 18.3 \\
\hline Total & 350 & 212 & & 60.6 \\
\hline
\end{tabular}

Source: Own Survey (2015)

\subsection{Prevalence of Major Gastrointestinal Nematode on Sex Basis}

From the total of 350 sheep examined coprologically for gastrointestinal nematode eggs, $60.6 \%$ were found positive. The prevalence was $89(67.4 \%)$ in male and significantly higher $(\mathrm{P}<0.05)$ than $123(56.4 \%)$ in female (Table 2).

Table.2: Prevalence of gastrointestinal nematode parasite in sex category in selected districts during the study period.

\begin{tabular}{lccccc}
\hline Sex (risk factor) & $\begin{array}{l}\text { No. } \begin{array}{r}\text { of } \\
\text { examined }\end{array} \\
\text { Male }\end{array}$ animal $^{\text {No. of animal }}$ & $\begin{array}{l}\text { No. } \\
\text { infected }\end{array}$ & P-value \\
Female & 218 & $89(67.4 \%)$ & & 0.043 \\
\hline Total & $\mathbf{3 5 0}$ & $123(56.4 \%)$ & 4.167 & \\
\hline Source: Own Survey (2015) & $\mathbf{2 1 2 ( 6 0 . 6 \% )}$ & &
\end{tabular}

\subsection{Prevalence of Major Gastrointestinal Nematode by Age category}

Adult animals tend to be more susceptible to nematode as compared to young. Infection prevalence was 
significantly higher $(\mathrm{P}<0.05)$ in adult animal $130(66.7 \%)$ than young animal $82(52.9 \%)$ in table 3 .

Table.3: Prevalence of major gastrointestinal nematode parasite by age category in study area.

\begin{tabular}{lcccc}
\hline Age (risk factor) & No. of animal examined & No. of animal infected & $\mathbf{X}^{\mathbf{2}}$ & P-Value \\
\hline Young & 155 & $82(52.9 \%)$ & & 0.011 \\
Adult & 195 & $130(66.7 \%)$ & 6.850 & \\
\hline Total & $\mathbf{3 5 0}$ & $\mathbf{2 1 2}(\mathbf{6 0 . 6 \% )}$ & & \\
\hline
\end{tabular}

Source: Own Survey (2015)

\subsection{Prevalence of Major Gastrointestinal Nematode in Different Body Condition Scores}

From the total of 350 sheep examined, 80, 159 and 111 were categorized as having good, medium and poor body condition scores. Infection prevalence was slightly higher in animal with poor body condition when compared to that of medium and good body condition scores. The overall infection prevalence according to body condition score, $64.9 \%, 61.6 \%$ and $52.5 \%$ with poor, medium and good, respectively. However, the chi-square $\left(\chi^{2}\right)$ test value indicated that there was no statistically significant difference $(\mathrm{P}>0.05)$ in prevalence of gastro-intestinal nematode infection of sheep between different body condition score (Table 4).

Table.4: The prevalence of major gastrointestinal nematode in different body condition scores.

\begin{tabular}{|c|c|c|c|c|}
\hline $\begin{array}{l}\text { Body condition (risk } \\
\text { factor) }\end{array}$ & $\begin{array}{l}\text { No. of animal } \\
\text { examined }\end{array}$ & No. of animal infected & $\mathrm{X}^{2}$ & P-value \\
\hline Good & 80 & $42(52.5 \%)$ & & \\
\hline Medium & 159 & $98(61.6 \%)$ & 3.114 & 0.211 \\
\hline Poor & 111 & $72(64.9 \%)$ & & \\
\hline Total & 350 & $212(60.6 \%)$ & & \\
\hline
\end{tabular}

\subsection{Prevalence of Major Gastrointestinal Nematode in Different Peasant Associations (PAs)}

From total of the sheep examined in the five peasant association (PAs), samples from Ensena Usme (58.6\%), Dobana Gola (67.1\%), Wurb (65.7\%), Bamo (55.7\%) and Gidena Aborat (55.7\%) showed GIT nematode infection prevalence. The chi-square $(\chi 2)$ test value indicated that there was no statistically significant difference $(\mathrm{P}>0.05)$ in prevalence of gastro-intestinal nematode infection of sheep between these peasant associations (PAs) Table 5.

Table.5: Prevalence of major gastrointestinal nematode in different peasant associations (PAs).

\begin{tabular}{lcccc}
\hline $\begin{array}{l}\text { Peasant associations } \\
\text { (PAs) }\end{array}$ & $\begin{array}{l}\text { No. } \begin{array}{c}\text { of } \\
\text { examined }\end{array} \\
\text { Ensena Usme }\end{array}$ animal $^{\text {No. of animal infected }}$ & $\mathbf{X}^{\mathbf{2}}$ & P-value \\
Dobana Gola & 70 & $41(58.6 \%)$ & & \\
Wurb & 70 & $47(67.1 \%)$ & 3.541 & 0.482 \\
Bamo & 70 & $46(65.7 \%)$ & & \\
Gidena Aborat & 70 & $39(55.7 \%)$ & \\
\hline Total & $\mathbf{3 5 0}$ & $\mathbf{2 1 2}(\mathbf{6 0 . 6 \% )}$ & \\
\hline
\end{tabular}

Source: Own Survey (2015)

\section{DISCUSSION}

The coprological examination done for this study using direct faecal floatation method revealed an overall gastro-intestinal nematode prevalence of $60.6 \%$ of sheep originating from this area which were being parasitized at least by one type of gastrointestinal nematodes. However, apparent difference was noted, the present finding agrees with previous studies by coprological examination in some areas of Ethiopia (Diriba and Birhanu, 2013) 68.1\% in Asella and (Tesfalem, 1989) 52.2\% in Bale and (Ahmad, et al., 2012) 62.8\% from abroad. This finding is lower than the results of previous surveys in sheep in some areas of Ethiopia $76.3 \%$ (Moti, 2008) and 79.09\% (Achenef, 1997). The possible explanation of this deference could be due to extensive use of antihelmintics by the farmers, difference in agro-climatic conditions that could support prolonged survival and development of infective larval stage of most nematodes (Rossanigo and Grunder, 1995). Furthermore, management system of animals and sample size considered could also contribute in the difference of the prevalence (Regassa et al., 2006). But, this result is higher than the work of (Jejaw, et al.., 2014) 41.9\% in Dembia district, North West Ethiopia. This difference might be due to the difference between the management system of examined animals and geographical and environmental location of the area.

The coprological investigation in the present study revealed the presence of Strongyles, Strongyloides, Trichuris spps and Ascaris spps as single and mixed infections in sheep. These mixed infections were mostly 
Strongyle and Strongyloides. Accordingly, similar prevalence of gastrointestinal nematodes results agrees with reports of previous studies conducted in Ethiopia as 8.2\% Strongyloides and 5\% Trichuris in Debre Zeit (Tigist, 2008); 3.3\% Trichuris species in Bedele (Temesgen, 2008) and 4.5\% Trichuris species in Western Oromia (Ragassa et al., 2006). Other comparatively very large coproscopic examination report was 97.03\% Strongyles type, $45.22 \%$ Strongyloides and 30.25\% Trichuris species in eastern part of Ethiopia (Abebe and Eseyas, 2001). These mixed infections have been suggested to be an important cause of morbidity and loss of production in sheep (Kumsa et al., 2011).

This study showed that Strongyles having direct life cycle were the most prominent among those that were positive for gastrointestinal nematode parasites of animals. Therefore, Strongyles are gastrointestinal nematodes of greatest importance in sheep, and causes serious direct and indirect losses in most parts of the country by (Hailuleul, 2002) in Wolayta Soddo and (Yosef, 1993) in Asella. Strongyloides and Trichuris species were poorly represented. This agrees with the idea of (Urquhart et al., 1996) which indicates only young are more susceptible to these parasites while adults usually develop certain immunity. (Soulsby, 1986) also indicated the presence of resistance for Trichuris in sheep over eight months and not usually severe enough to cause clinical disease. Clinical signs are seen mainly in the young and appear only in case of severe infection.

The present study shows that statistically significant differences $(\mathrm{P}<0.05)$ between different sex groups with nematode prevalence higher in male than female. The present result in agreement with (Gualy et al., 2006) and (Raza et al., 2007) from abroad had documented higher prevalence of nematode infection in rams. The possible explanations of the present result are that difference between females and males in susceptibility to parasite infection are probably caused by a difference in behavior, morphology or physiological status of sex. The different hormonal status of sexes may affect the immunological responses of sheep to gastrointestinal nematodes (Gauly et al., 2006). Effect of sex on the resistance level against GI parasites was reviewed by (Barger, 1993) and reported that difference in resistance level were significant after puberty only. The difference in resistance level after puberty is due to estrogen stimulatory effect on immune response against GIT nematodes while androgen suppresses the immune response (Seli and Arici, 2002) and this is the reason that males are more susceptible to infectious diseases including nematode parasites than female. However, in contrast with this result, (Urquhart et al., 1996) and (Dagnachew et al., 2011) reported that female animals are more susceptible to parasitism. It was assumed that sex was a determinant factor influencing prevalence of parasitism and females were more prone to parasitism during pregnancy and peri-parturient period due to stress and decreased immune status. These condition increase the prevalence of nematode infection rate in female were not found in the present study.

The present study further revealed that age of the animal did show significant association $(\mathrm{P}<0.05)$ with the prevalence of the parasites. In this study adult sheep have higher nematode infection rate than young. Age was considered an important risk factor in GI nematodes (Raza et al., 2007). The present result was in agreement with (Hassan et al., 2011) in Chittagong, Bangladesh and (Kulisic et al., 2013) in Eastern Serbia reported high prevalence rate in adults as compared to young sheep. The possible explanation is that this could be the result of longer exposition of adult sheep to the parasite eggs and larvae during several grazing seasons. There are also special conditions encountered during peri-perturient rise in nematode eggs excretion, as early as two weeks before lambing, and persisted up to eight weeks post-partum when lambing, and took place during the wet seasons (Ng'ang'a et al., 2006). Thus, pregnant or lactating ewes became the major shadier of nematode eggs without showing sever clinical sign. In addition the influence of grazing method used for the animals was significant for prevalence of gastrointestinal nematode infections. Sheep kept under different grazing management showed high prevalence in tethered animals followed by those maintained under alternate use of tethering and open grazing. In open grazing system, the low prevalence observed could indicate that animals freely grazed in the extensive grazing field had less exposure to infective larvae on the pasture or may have better resistance to the worm challenge than tethered animals (Takele et al., 2013). Since mixed crop-livestock production predominates in the area some farmers used to tether their older and adult sheep and allow lambs to graze freely. This situation cloud results in the present higher prevalence of nematode in the adult than young. However, the present result was not in line with several authors (Githigia et al., 2005), (Taswar et al., 2010) and (Degnachew et al., 2011) they have documented that adult and old animals develop acquired immunity against nematode infections as they get mature due to repeated exposure and this will help expel the parasite before it establish itself in the gastrointestinal tract. Which might reduce the infection rate was not found in the present study.

In the present study, the sheep with poor body condition seems to have higher prevalence of major gastrointestinal nematodes than other groups. However, it was not statically significant $(\mathrm{p}>0.05)$. This agrees with (Keyyu et al., 2006), (Nigatu, 2008), (Kanyari et al., 2009) and (Jijaw et al., 2014). The possible reason for slightly higher prevalence in weak animals of the host species could be that these animals usually have a comparatively weak immune system which does not fight with the infections to the same extent as that of a healthy animal's immune system (Kuchai et al., 2011). This poor body condition might be due to malnutrition or 
other concurrent disease and the present parasitic infection which lead to poor immunological response to infective stage of the parasites. Well-fed animals develop good immunity that suppresses the fecundity of the parasites (Bisset et al., 1986).

Similarly, in the present study there is no statistical significant difference $(\mathrm{P}<0.05)$ observed between the different studies sites (peasant associations). This also agrees with (Armour, 1980) who reported no significant difference was found in animals reared in similar geographical areas. This similarity might be due to the similarity between the management system of examined animals, geographical and environmental location of the area and they have the same agro ecology. Meanwhile, effects of different agro-ecology and geographic area showed significant difference in the prevalence of nematode infection rate (Demelash et al., 2006).

\section{CONCLUSION AND RECOMMENDATIONS}

Gastrointestinal nematode parasites are the major animal health constraints in sheep production and contributing loss in productivity and economy. The present study result indicated that gastrointestinal nematodes are of the major helminthosis of sheep in Meskan district, Gurage zone, with overall prevalence $60.6 \%$. This study was based solely on coproscopic examination for detection of gastrointestinal nematode eggs. The result has provided an insight to the current prevalence and associated risk factors. Age and sex were potential risk factors associated with prevalence of gastrointestinal nematode infection in the study area. Though prevalence of nematode with body condition did not show significant association, animal with poor body condition have higher nematode infection than other group. There are also weak status of animal health services and lack of proper management in the study area. Crop-livestock mixed farming is highly dominated and most land is cultivated so that communal grazing and tethering of the animal is practiced in the area on marginal and a piece of land. Therefore based on the above conclusions the following recommendation are directed

$>$ The parasites detected as Strongyle-type should be identified at genus and species level using further laboratory techniques.

$>$ Predisposing factors such as poor management and concurrent chronic diseases should be avoided.

$>$ There should be Strategic anthelminthic treatments of sheep with broad spectrum anthelminthic at the beginning of rain season and at the end of dry season to reduce the worm burden and minimize pasture contamination with larvae

$>$ Applying rotational grazing system for different seasons would reduce pasture contamination and separating the most susceptible adult animals especially pregnant and lactating ewes from flocks, which are a possible source of pasture contamination. Finally there should be Support of veterinarians and animal healthy extensions in giving professional advices regarding preventive and control measures against gastrointestinal helminthes parasites and prevention in the area.

\section{REFERENCES}

Abebe, W., and Eseyas, G. (2001): Survey of Ovine and Caprine gastrointestinal Helminthosis in Eastern part of Ethiopia during the dry season of the year. Rev. Vet. Med. 152 (5), 379-385.

Achenef, M. (1997): Observation on Ovine gastrointestinal nematodiasis and coenurosis in sheep populations of Ethiopian highland, Debre Berhan, North Showa. DVM Thesis, Faculty of Veterinary Medicine, Addis Ababa University, Debre- Zeit, Ethiopia.

Ahmad, I., Eva, M., Birgit, S., and Matthias, G. (2012): Gastrointestinal nematode infections in German sheep. Par. Res. 110, 1453-1459.

Armour, J. (1980): The Epidemiology of Helminthes diseases in farm animals. Vet. Par. 6, 7-46.

Barger, I. A. (1993): Influence of sex and reproductive status on susceptibility of ruminants to nematode parasitism. Inter. J. Par. 23 (4), 463-469.

Bisset, V., Lassoff, A., Douch, P. G. C., Jonas, W. E., West, C. J., and Green, R. S. (1986): Burdens and immunological response following natural challenges in Romney lambs selectively bred for low or high faecal eggs count. J. Vet. Par. 61, 249-263.

Charles, M.H. (2006): Diagnostic veterinary Parasitology. $3^{\text {rd }}$ ed. Stilous: Elsevier science.

CSA (2013): Report on Livestock and livestock characteristics (Private peasant holdings), Agricultural Sample Survey. Central Statistical Agency (CSA), Federal Democratic Republic of Ethiopia, Addis Ababa. Volume II: (Statistical Bulletin 570).

Dagnachew, S., Amamute, A., and Temesgen, W. (2011): Epidemiology of Gastrointestinal Helminthiasis of small ruminants in selected sites of North Gondar zone, Northwest Ethiopia. Eth. Vet. J. 15, 57-68.

Demelash, B., Yilma, J., and Hassen, C. (2006): Ovine Helminthosis is major health constraints to productivity of sheep in Ethiopia. DVM Thesis, Faculty of Veterinary Medicine, Awassa University, Awassa, Ethiopia.

Diriba, L., and Birhanu, A. (2013): Prevalence of Ovine Gastrointestinal Nematodes in and around Asella, South Eastern Ethiopia. J. Vet. Med. Anim. Health. 5 (8), 222-228. 
Gauly, M., Schackert, M., Hoffmann, B., and Erhardt, G. (2006): Influence of sex on the resistance of sheep lambs to an experimental Haemonchus contortus infection. Deut. Tierarztl. Woch. 113, 178-181.

Githigia, S. M., Thamsborg, S. M., Maingi, N., and Munyua, W. K. (2005): The epidemiology of gastrointestinal nematodes in Goats in the low potential areas of Thika District, Kenya. Bul. Anim. Health. Prod. Africa. 53, 5-12.

Hailuleul, N. (2002): Prevalence on Gastrointestinal Helminthes of small ruminants in and around Wolayta Soddo, Southern Ethiopia. DVM Thesis, Faculty of Veterinary Medicine, Addis Ababa University, Debre Zeit, Ethiopia.

Hassan, M. M., Hoque, M. A., Islam, S. K. M. A., Khan, S. A., Roy, K., and Banu, Q. (2011): A prevalence of parasites in black Bengal goats in Chittagong, Bangladesh. Inter. J. Livestock. Prod. 2 (4), 40-44.

Jejaw, M., Basaznew, B., and Mersha, C. (2014): Major Gastrointestinal Nematodes of Small Ruminants in Dembia District, Northwest Ethiopia. Eur. J. App. Sci. 6 (2), 30-36.

Kanyari, P. W., Kagira, J. M., and Mhoma, R. J. (2009): Prevalence and Intensity of Endo-Parasites in small ruminants kept by farmers in Kisumu Municipality, Department of Veterinary Pathology, Microbiology and Parasitology, Faculty of Veterinary Medicine, University of Nairobi, Kenya.

Kanyari, P. W. N., Kagira, J. M., and Mhoma, R. J. (2009): Prevalence and intensity of Endo-parasites in small ruminants kept by farmers in Kisumu Municipality, Kenya. Livestock Res. Rural Dev. 21 (11), 01-11.

Kaplan, M. (2006): Update in parasite control in small ruminants: Addressing the challenges posed by multipledrug resistant worms. In: Proceeding of the American Association of Bovine practioners, Saint Paul, MN, USA, September 21-23, 2005.

Keyyu, J. D., Kassuku, A. A., Msalilwa, L. P., Monrad, J., and Kyusgaard, N. C. (2006): Cross sectional prevalence of helminth infections in cattle on traditional, small scale and large-scale dairy farms in Iringa district, Tanzania. Vet. Res. Comm. 30, 45-55.

Kuchai, J. A., Chishti, M. Z., Zaki, M. M., Javid, A., Dar, S. A., Muzaffar, R., and Hidayatullah, T. (2011): Epidemiology of helminth parasites in small ruminants of Ladakh, India. J. Anim. Feed Res. 1 (5), 239-242.

Kulisic, Z., Aleksic, N., Dordevic, M., Gajic, B., Tambur, Z., Stevanovic, J., and Stanimirovic, Z. (2013): Prevalence and intensity of infection with gastrointestinal nematodes in sheep in eastern Serbia. Act. Vet. 63 (4), 429-436.

Kumsa, B., Tadesse, T., Sori, T., Dugum, R., and Hussen, B. (2011): Helminths of sheep and goats in Central Oromia (Ethiopia) during the dry season. J. Anim. Vet. Adv. 10, 1845-1849.

Meskan District Agricultural and Rural Development Bureau (2013): Butajira

Moti, W. (2008): Prevalence of gastrointestinal nematode of sheep and goat in and around Welinchity, Central Ethiopia. DVM Thesis, Faculty of Veterinary Medicine, Haramaya University, Haramaya, Ethiopia.

Ng'ang'a, C. J., Kanyari, P. W., Maigi, N., Munyua, W. K. (2006): The effect of weather on the occurrence and magnitude of peri-parturient rise in Trichostrongyloid nematode egg output in Dorper in a semi-arid area of Kajiado Districct of Kenya. Trop. Anim. Health Prod. 38, 389-395.

Nigatu, K. (2008): Gastrointestinal Helminthosis of Sheep in Awi Zone, northwestern Ethiopia. Gl. Vet. 12, 121129.

Raza, M. A., Iqbal, Z., Jabbar, A., and Yaseen, M. (2007): Point prevalence of gastrointestinal helminthiasis in ruminants in southern Punjab. Pak. J. Helm. 81, 323-328.

Regassa, F., Sori, T., Dhuguma, R., and Kirros, Y. (2006): Epidemiology of Gastrointestinal Parasites of Ruminant in Western Oromia, Ethiopia. Inter. Appl. Res. Vet. Med. 4 (1), 7-11.

Rossanigo, C. E., and Grunder, L. (1995): Moisture and temperature requirements in feces for the development of free living stages of gastrointestinal nematodes of sheep and cattle and deer. J. Helm. 67, 357-362.

Samson, L., and Frehiwot, M. (2010): Prevalence of Small Ruminant Trypanosomosis and Tsetse Fly Challenge in Upper Didessa Vally, Ethiopia. Adami-Tullu Agriculture Research Center, Ziway, Ethiopia, Pp: 215.

Seli, E., and Arici, A. (2002): Sex steroids and the immune system. Immunol. Allergy clinic North Am. 22, $407-$ 408.

Solomon, M., and Rahmento, A. (2010): Observation on major welfare problems of equine in meskan district, southern Ethiopia. Livestock Res. Rural Dev. 22 (3), 12-16.

Soulsby, E. (1982): Helminths, Arthropods and Protozoa of Domesticated Animals. $7^{\text {th }}$ ed. London: Bailliere Tindall, Pp 212-258.

Soulsby, E. (1986): Helminthes, arthropods and protozoa of domestic animals $7^{\text {th }}$ ed. London, UK: Bailliere Tindall. Pp 247-250.

Takele, S., Yacob, H., and Getachew, T. (2013): Epidemiology of gastrointestinal nematode of Horro sheep in Western Oromiya, Ethiopia. J. Vet. Med. Anim. Health. 5(10), 296-304.

Takelye, B. (1991): Epidemiology of Endo-parasites of small ruminants in sub-Saharan Africa. In: Proceedings of the $4^{\text {th }}$ National livestock Improvement Conference, Addis Ababa, Ethiopia, Pp 7-15. 
Taswar, Z. S., Ahmad, M., Lashari, H., and Hayat, C. S. (2010): Prevalence of Haemonchus contortus in sheep at Research Centre for Conservation of Sahiwal Cattle (RCCSC) Jehangirabad, District Khanewal, Punjab, Pakistan. Pak. J. Zoo. 42, 735-739.

Temesgen, T. (2008): Study on Prevalence of Ovine Gastrointestinal Parasite in and around Bedele .DVM Thesis, Faculty of Veterinary Medicine, Haramaya University, Haramaya, Ethiopia.

Tesfalem, T. (1989): Prevalence of GI helminthes of small ruminants in Mendeyo province of Bale administrative region, Ethiopia, DVM thesis, FVM, AAU, Debrezeit, Ethiopia.

Thrusfield, M. (2005): Surveys in Veterinary Epidemiology, $3^{\text {rd }}$ ed. U.K: Black Well Science Ltd. Pp 178-198.

Tigist, T. (2008): Gastrointestinal parasitosis of small ruminants in and around Debre Zeit. DVM Thesis, Faculty of Veterinary Medicine, Haramaya University, Haramaya, Ethiopia.

Tilahun, H., and Schmidt, E. (2012): Spatial Analysis of Livestock Production Patterns in Ethiopia. ESSP II Working Paper 44. International Food Policy Research Institute/Ethiopia Strategy Support Program II, Addis Ababa, Ethiopia.

Tsedeke, K. K. (2007): Production and Marketing systems of sheep and goats in Alaba, Southern Ethiopia. MSc Thesis, Department of Animal and Range Sciences, Awassa College of Agriculture, School of graduate studies, Hawassa University, Awassa, Ethiopia.

Urquhart, G. M., Armour, J., Duncan, J. L., Dunn, A. M., and Jennings, F. W. (1996): Veterinary Parasitology. $2^{\text {nd }}$ ed. United Kingdom: Blackwell science. Pp 307-308.

Yosef, S. (1993): Prevalence of Ovine Gastrointestinal Helminthes in and around Asella. DVM Thesis, Faculty of Veterinary Medicine, Addis Ababa University, Debre Zeit, Ethiopia.

Zuk, M., and McKean, K. A. (1996): Sex differences in parasite infections patterns and processes. Int. J. Para. $26,1009-1023$ 